\title{
VÍSPERAS DE MENOS: LA PRODUCCIÓN CIENTÍFICA DE LOS MÉDICOS ESPAÑOLES EN MARRUECOS ANTES DEL PROTECTORADO (1884-1906) ${ }^{1}$
}

\author{
Francisco Javier Martínez Antonio \\ Investigador postdoctoral Marie Curie \\ SPHERE, CNRS-Université Paris Diderot, Francia
}

Resumen: El periodo previo al establecimiento del Protectorado español en Marruecos en 1912 no fue el más prolífico en términos de producción científica médica. No obstante, en nuestra opinión, se trató del más importante históricamente en lo que respecta al alcance y al potencial de dicha producción. El impulso político a las iniciativas españolas en Marruecos desde mediados de la década de 1880 se tradujo en un aumento del número de médicos españoles, cuya actividad se enmarcó en un triple esquema: médicos consulares, médicos en la corte del Sultán y médicos de la Comisión del Cuerpo de Estado Mayor. El resultado de sus actividades fue un corpus de informes, manuscritos y publicaciones, generalmente olvidado, pero que constituyó el intento mas ambicioso de España de elaborar una imagen de la salud y la enfermedad en el conjunto de Marruecos. Además de identificar qué médicos ejercieron durante este periodo y enumerar sus trabajos científicos, analizaremos dos obras especialmente relevantes: El cólera en Tánger de Felipe Óvilo y Topografía médica del Fahs de Tánger y las cábilas de Anyera de Ramón Fiol.

Abstract: The years predating the establishment of the Spanish Protectorate in Morocco in 1912 were not the most prolific interms of the scientific output of Spanish physicians residing in that country. In our opinion, however, they were the most important in the history of Spanish intervention in Marocco in research scope and potential. Political backing to initiatives in Morocco from the mid-1880s resulted in higher numbers of Spanish physicians, working in: consulates, the Sultan's court and the Spanish Topographic Commision. The result of their activities was a corpus of reports, manuscripts and

${ }^{1}$ Este trabajo ha sido realizado con la ayuda de un contrato postdoctoral del programa Marie Curie Intra-European Fellow ships for Career Development de la Unión Europea. 
publications which, though hitherto forgotten, stood as the most serious attempt ever made by Spain of drawing a comprehensive picture of health and disease in Morocco. Besides identifying individual physicians and enumerating their scientific writings, we will analyze two especially relevant works: El cólera en Tánger, by Felipe Óvilo and Topografía médica del Fahs de Tánger y las cábilas de Anyera, by Ramón Fiol.

Palabras clave: Médicos españoles, Marruecos, final del siglo XIX, producción científica-

Keywords: Spanish physicians, Morocco, late 19th century, scientific output.

\section{Introducción}

El establecimiento del Protectorado español en Marruecos en octubre de 1912 se tradujo en un crecimiento exponencial de las publicaciones científico-médicas a cargo de una parte de los varios centenares de médicos (y algunas médicas) que ejercieron allí hasta la independencia del país en 1956. Esta producción, más o menos abundante según el momento concreto, vio la luz en forma de todo tipo de trabajos tanto en el Protectorado, como en Ceuta y Melilla y en la península. Entre las revistas locales especializadas cabe señalar Marruecos sanitario (1929-31) o el Anejo al Boletín de Información Estadística, Sanitaria y Demográfica (1939-48). Entre las revistas médicas de la península y plazas de soberanía podríamos consignar la Revista de Sanidad Militar (1911-36), Los Progresos de la Clínica (1913-1936), La España Médica (191136), Higia (1917-¿?), Revista Hispano-Africana de Medicina y Cirugía (193336), Revista Clínica Española (1940), Medicina de los Países Cálidos (1928-36) o La Medicina Colonial (1943-56) entre otras. También se publicaron regularmente trabajos médicos en revistas no especializadas, destacando África [Revista de Tropas Coloniales] (1924-78) y Cuadernos de Estudios Africanos [y Orientales] (1946-57). Entre los organismos y editoriales que publicaron monografías y folletos sobre temas médico-sanitarios cabría señalar la Alta Comisaría de España en Marruecos y la Editorial Tánger en el Protectorado; la Imprenta de la Revista África y la Imprenta Imperio en Ceuta; la Tipografía de La Gaceta en Melilla; y los Talleres del Depósito de la Guerra o el Instituto de Estudios Africanos del CSIC en la península. 
Ningún otro periodo, ni anterior ni posterior, vio tal volumen de producción científica española sobre Marruecos. No obstante, creemos que el periodo previo al establecimiento del Protectorado, más exactamente el comprendido entre la década de 1880 y 1906, fecha de la Conferencia de Algeciras que dio comienzo a la intervención efectiva de España y Francia en Marruecos, tuvo mayor importancia para España desde el punto de vista de la producción científica. Tal importancia no se deriva del número de publicaciones o de su nivel científico (menores), sino de su alcance y su potencial (mayores). Por una parte, en aquellos años los médicos españoles abarcaron con sus trabajos e investigaciones la mayor parte de Marruecos y no las dos pequeñas y marginales regiones situadas en los extremos norte y sur del país que formaron el Protectorado a partir de 1912. Hubo, propiamente, una producción científica hispana sobre Marruecos, aunque ciertas zonas que luego estarían bajo control español recibieran ya una atención preferente en dicho periodo. Por otra parte, aunque, como veremos en este artículo, buena parte de dicha producción permaneció inédita, habría sido cuestión de tiempo que esos trabajos dieran lugar a líneas de estudio con publicaciones y que sobre dicha base se edificara una administración sanitaria y una investigación biomédica de mayor entidad que las que existieron en el Protectorado. La importancia que podría haber tenido Marruecos como espacio de modernización científica e institucional para la medicina española no la tuvo el Protectorado por la falta de continuidad con aquellos primeros pasos aparentemente modestos que, sin embargo, serían vísperas de menos.

La pérdida de influencia de España en Marruecos a partir de 1906 (efecto colateral a menudo olvidado del desastre del 98) tuvo como resultado, entre otras cosas, el olvido de lo que, sin embargo, fue un corpus notable de trabajos científico-médicos. En este trabajo trataremos de ofrecer una breve panorámica sobre los mismos. Las fechas del periodo de estudio seleccionado son 1884, año del nombramiento del primer médico de la Comisión de Estado Mayor en Marruecos y de la llegada del doctor Cenarro aTánger, y 1906, año de la Conferencia de Algeciras. Comenzaremos nuestro trabajo presentando una relación lo más completa posible de los médicos españoles instalados en Marruecos en dicho periodo y de los puestos que ocuparon. Pasaremos después a enumerar, también lo más exhaustivamente posible, sus escritos y publicaciones. Fi- 
nalmente, analizaremos con detalle el contenido científico y las implicaciones, tanto para la medicina como para la política española en Marruecos, de dos obras que juzgamos especialmente relevantes.

\section{Médicos españoles en Marruecos ${ }^{2}$ 1884-1906}

Desde el final de la Guerra de África, y dejando a un lado el hecho excepcional de la ocupación de Tetuán entre 1860 y 1862, el número de médicos españoles en Marruecos comenzó a aumentar tímidamente. En un principio, tal aumento fue debido esencialmente a la iniciativa oficial. Se nombró por primera vez un médico agregado a la Legación de España en Tánger, puesto ocupado por los facultativos militares Francisco Esteve Soriano hasta 1868 y Jaime Isern Zulueta hasta 1877, aunque no se lograra extender dicha medida a otras ciudades salvo a Tetuán, donde el doctor Francisco de Palma residiría la mayor parte de las siguientes cuatro décadas, ni tampoco a la corte del sultán ${ }^{3}$.Hubo también algún médico civil vinculado a actividades diplomáticas o militares. Especial renombre adquirió el malagueño o ceutí Manuel Tomás Rodríguez, instalado en Rabat desde 1861 donde trabó amistad con el viajero y espía Joaquín Gatell y Folch, el caíd Ismail. El sultán Mohammed IV llegó a solicitar sus servicios para sí mismo y para su harén, hecho que sería aprovechado con fines políticos y de espionaje por el jefe de la Legación Francisco Merry y Colom y que se traduciría en diversas amenazas de expulsión del país para el médico, a pesar de lo cual seguiría residiendo en Rabat al menos hasta $1876^{4}$. Al margen de la iniciativa oficial, algunos médicos y dentistas del sur de la península comenzaron quizás por entonces a realizar visitas periódicas o estancias temporales en las ciudades costeras

\footnotetext{
${ }^{2}$ No incluimos en este apartado los médicos militares y civiles de Ceuta y Melilla que realizaron desplazamientos a territorio marroquí y publicaron trabajos científicos sobre Marruecos en este periodo.

${ }^{3}$ MARTÍNEZ ANTONIO, Francisco Javier, Intimidades de Marruecos. Miradas y reflexiones de médicos españoles sobre la realidad marroquí a finales del siglo XIX, Madrid, Miraguano, 2009, p. 13; GONZÁLEZ, Isidro, El retorno de los judíos, Madrid, Nerea, 1991, p. 76.

${ }^{4}$ MARTÍNEZ ANTONIO, Francisco Javier, Viajes por Marruecos de Joaquín Gatell (el caíd Ismail), Madrid, Miraguano, 2012, p. 105-106.
} 
para ofrecer sus servicios a las pequeñas colonias de europeos y a las élites locales. Un caso excepcional podría haber sido el del doctor Tadeo Martínez Cobos, antiguo médico de la Armada que quizás se había exiliado en Tánger al finalizar el Sexenio y que fue enviado por el Consejo Sanitario a Fez y Mequínez en 1877 para obtener información sobre la epidemia de cólera que afectaba al interior de Marruecos y que terminaría extendiéndose por todo el país ${ }^{5}$.

Esta situación cambió a mediados de la década de 1880. En ese momento, los gobiernos del Partido Liberal, a través de sus ministros de Estado Segismundo Moret y el Marqués de la Vega de Armijo, intensificaron notablemente la acción oficial española en Marruecos, incluidas las iniciativas médico-sanitarias. Fue entonces cuando serían destinados a la Legación de Tánger dos médicos militares que habían adquirido una larga experiencia de trabajo fuera de la península por sus estancias en Cuba y Puerto Rico. El primero en llegar sería el doctor Severo Cenarro Cubero en 1884 y también fue el que más permaneció en Tánger, hasta su prematuro fallecimiento en enero de $1898^{6}$. Pero sería el doctor Felipe Óvilo Canales quien actuaría como auténtico líder en la sombra no solo de los proyectos médicos, sino de muchas iniciativas de la política española en Marruecos en esos años. [1] Óvilo llegó a Tánger en julio de 1886 directamente enviado por Moret a través de la Sociedad Española de Africanistas y Colonistas, de la que ambos eran miembros, para actuar como una especie de agente suyo sobre el terreno. Mientras Cenarro ocupaba el puesto de médico agregado a la Legación, Óvilo fue nombrado "agregado militar" y como tal permanecería hasta casi el final de su estancia tangerina en $1896^{7}$.

Óvilo, con la ayuda valiosa de Cenarro, tradujo el ideal regeneracionista español en Marruecos, liderando un proyecto de intervención en el país vecino basado en los mismos principios que guiaban aquel movimiento reformista en la península ${ }^{8}$. En el ámbito médico-sanitario, dicho proyecto se tradu-

${ }^{5}$ RAYNAUD, Louis, Étude sur l'hygiène et la médecine au Maroc, Alger, Léon, 1902, p. 88.

${ }^{6}$ Cenarro estuvo destinado en Puerto Rico entre 1877 y 1880 y en Cuba entre ese año y 1883. Archivo General Militar de Segovia (AGMS), Hoja de servicios de Severo Cenarro Cubero, C2540.

${ }^{7}$ Óvilo estuvo destinado en Cuba entre 1870 y 1877, es decir, durante buena parte de la llamada Guerra de los Diez Años. AGMS, Hoja de servicios de Felipe Óvilo Canales, O-25. 
jo, por una parte, en la potenciación del rol del Consejo Sanitario de Tánger como organismo director de la salud pública en el país. Cenarro asumió el cargo de "médico asesor" del mismo durante sus años de estancia en Tánger con la idea de hacer valer las opiniones científicas sobre las políticas de los cónsules que integraban el Consejo y en última instancia sobre el poder de decisión que seguía conservando el sultán. Además, promovió la utilización y acondicionamiento de la isla de Mogador como lazareto para los peregrinos marroquíes que regresaban anualmente de su viaje a la Meca, consiguiendo que se utilizase regularmente en la década de $1890^{9}$. Por otra parte, el proyecto regeneracionista tuvo otra destacada expresión en la creación de una Escuela de Medicina en Tánger, dirigida por Óvilo, que comenzó ofreciendo una formación básica a algunos jóvenes marroquíes de buena familia y frailes franciscanos y que desde 1890 se transformó en centro de formación de médicos para el ejército marroquí. Óvilo y Cenarro se encargaron de impartir las enseñanzas teóricas y prácticas a un número de alumnos que ascendió a unos 15 o 20, algunos de los cuales se incorporaron posteriormente a unidades militares en diversas ciudades del país y participaron en expediciones armadas ${ }^{10}$. Finalmente, Óvilo y Cenarro consiguieron crear una Comisión de Higiene en Tánger en 1888 que desarrollaría progresivamente competencias de sanidad urbana y de la que Cenarro sería vicepresidente y único experto médico durante toda su estancia en la ciudad ${ }^{11}$. Ambos médicos se ocuparon también de asegurar la asistencia médica a la creciente colonia española en Tánger, tanto con visitas a domicilio como con su trabajo en el Hospital Español abierto en 1888 por iniciativa de la Misión Franciscana con el apoyo del Ministerio de Estado.

\footnotetext{
${ }^{8}$ MARTÍNEZ ANTONIO, Francisco Javier "Dos dedos de una misma mano: propuestas para un nuevo análisis de las relaciones hispano-marroquíes a finales del siglo XIX”, en MARTínEZ ANTONIO, Francisco Javier; GONZÁLEZ GONZÁLEZ, Irene, (eds.) Regenerar España y Marruecos. Ciencias y educación en las relaciones hispano-marroquíes a finales del siglo XIX, Madrid, CSIC-Casa Árabe, 2009, p. 21-58.

${ }^{9}$ MARTÍNEZ ANTONIO, Francisco Javier, "El doctor Severo Cenarro y los proyectos médicosanitarios de la España africana (1884-1898)", Cuadernos del Archivo Central de Ceuta, vol 17, 2010, p. 273-286.

${ }^{10}$ MARTÍNEZ ANTONIO, Francisco Javier, "The Tangier School of Medicine and its Physicians: A forgotten initiative of medical education reform in Morocco (1886-1904)”, Journal of the International Society for the History of Islamic Medicine, vol. 10-11, no 19-22, 2011-2012, p. 80-86.

${ }^{11}$ MARTÍNEZ ANTONIO, “El doctor Severo Cenarro”, p. 286-293.
} 
Desde Tánger, Óvilo y Cenarro pasaron a supervisar una red de “médicos agregados" a los consulados españoles tras la aprobación por parte del gobierno de esta medida en 1888. Se pretendía con ello, al margen de velar por la salud del personal diplomático, proporcionar asistencia médica a las colonias de españoles, ofrecer sus servicios a los notables musulmanes y hebreos de cada localidad, ocupar el cargo de médico asesor en las delegaciones del Consejo Sanitario y, ocasionalmente, auxiliar a unidades del ejército marroquí ${ }^{12}$. La mayoría de estos médicos eran médicos militares (y habían servido en $\mathrm{Cuba}^{13}$ ), aunque en algún caso se contó con médicos de la Armada, civiles e incluso hebreos marroquíes. Los primeros médicos consulares en ocupar su puesto a finales de 1888 fueron Simón Guevara Martínez en Mogador y Antonio Jordán Luna y Ramón Sáez García en los viceconsulados de Casablanca y Larache respectivamente ${ }^{14}$. Guevara sería relevado por Enrique Rebolledo (1895-96) y Francisco García Belenguer (1897) ${ }^{15}$. En Casablanca, Jordán sería sustituido por Joaquín Gamir Díaz-Colón (18971902), Rafael Alcaide (1903-04) y Antonio Moncada y Álvarez (1904-10). En Larache, tras la breve estancia de Sáez (1889), se sucedieron Ricardo Conejero López (1889-92), José Larrubia Domínguez (1893-1896), Julio Aldás Torres (1896-1897), Francisco Triviño Valdivia (1897-1901) y el ya aludido García Belenguer (1902-1907) ${ }^{16}$. En la Legación de Tánger, tras la marcha de Óvilo y el fallecimiento de Cenarro, pasaron a ocupar el puesto principal Joaquín Cortés Bayona (1898-1904), [2] que concentró las competencias de ambos como director de la Escuela de Medicina y médico consultor del Consejo y el ya mencionado Triviño (1904-1912), quien ya no ocupó ninguno de los dos cargos. Ambos contaron en Tánger con la ayuda de otros médicos militares como Ramón Fiol Jiménez y García Belenguer (1899.

\footnotetext{
${ }^{12}$ MARTÍNEZ ANTONIO, Intimidades de Marruecos, p. 15-16.

${ }^{13}$ En Cuba estuvieron Guevara en1881; Rebolledo en 1876-87; Gamir en 1877-83; Cortés en 1872-78; Jordán en 1877-84.

${ }^{14}$ La Iberia, 2 de septiembre de 1888.

${ }^{15}$ AGMS, Hoja de servicios de Enrique Rebolledo, R-173.

${ }^{16}$ MARTÍNEZ ANTONIO, Intimidades de Marruecos, p. 15. AGMS, Hoja de servicios de Francisco Triviño Valdivia, T-1175. Archivo Histórico del Ministerio de Asuntos Exteriores (AHMAE),Personal P107, Expediente 5258 Francisco García Belenguer.

${ }^{17}$ Ibidem.
} 


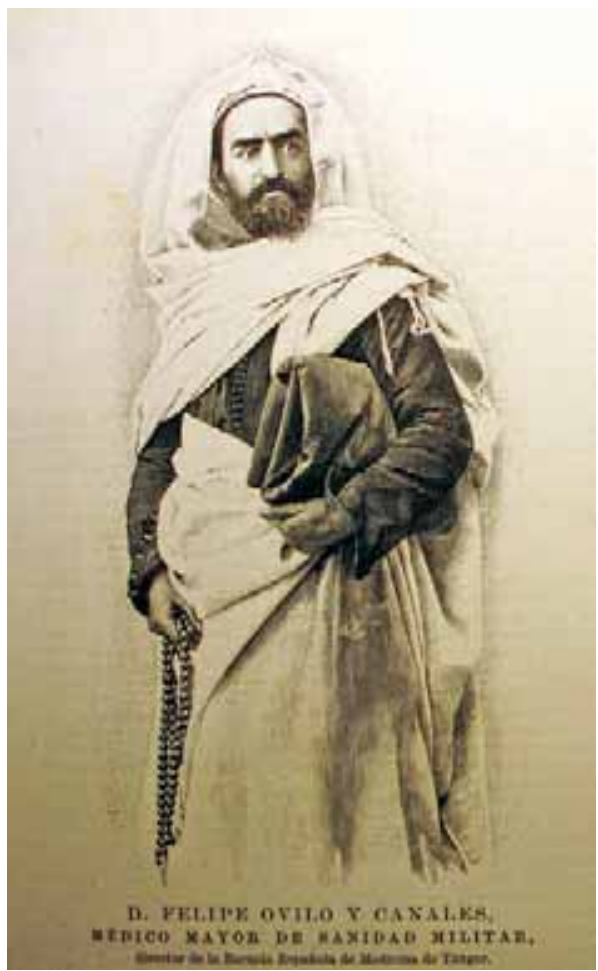

Fig. 1. Felipe Óvilo vestido a la usanza marroquí durante la embajada del general Martínez Campos a Marrakech en 1894.

Fuente: La Ilustración Española y Americana, Hemeroteca Digital de la Biblioteca Nacional de España.

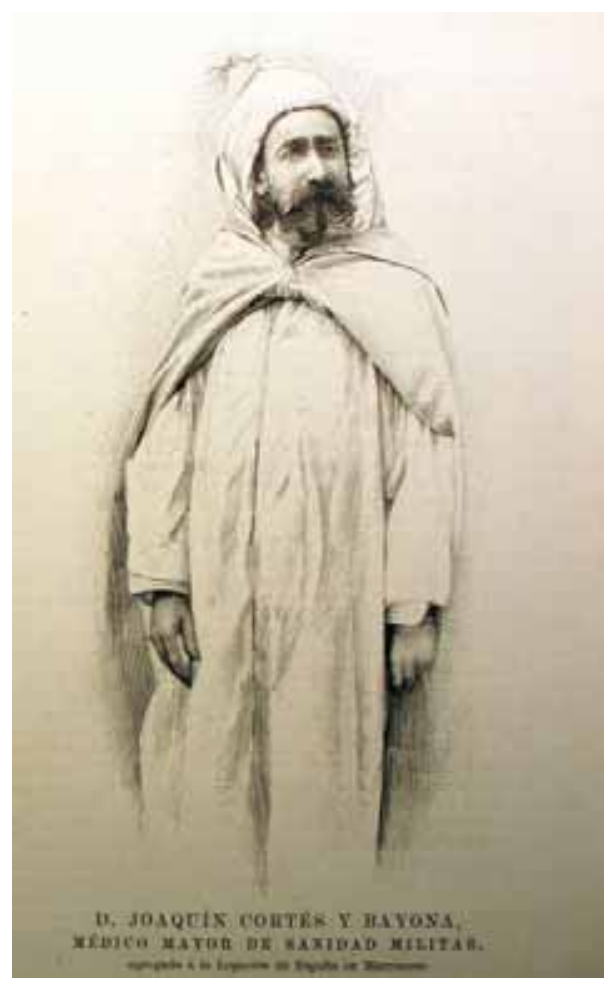

Fig. 2. Joaquín Cortés vestido a la usanza marroquí durante la embajada del general Martínez Campos a Marrakech en 1894.

Fuente: La Ilustración Española y Americana, Hemeroteca Digital de la Biblioteca Nacional de España.

Éste último había sustituido a Sotero García de Mayoral, médico civil que colaboró con Óvilo y Cenarro en la década de 1890 antes de convertirse en médico militar "provisional” agregado a la Legación en 1896-9918. Otro médico civil fue el gaditano Gustavo Prieto, que se instaló en Tánger en 1886 y fue reclutado ad hoc por Cenarro para organizar el lazareto de la isla de Mogador en 1891 y 1893 (este último año junto con su hermano José) ${ }^{19}$ y que luego ejerció como médico agregado al consulado de Rabat al menos en

${ }^{18}$ AHMAE,Personal P108, Expediente 5342 Sotero García de Mayoral.

${ }^{19}$ Al Mogreb al-Aksa, 28 de marzo de 1886, 21 de septiembre de 1891, 16 de septiembre de 1893. 
1895-9720. El doctor Manuel Ruiz de Conejo se estableció en Mazagán en los años 80 , llegando a ser nombrado médico del viceconsulado y delegado sanitario del Consejo en dicho puerto ${ }^{21}$. En Casablanca residía y tenía consulta privada (aunque quizás también colaboraba con el viceconsulado) el doctor Juan Antonio de Vera, quien se vio indirectamente implicado en el asesinato por parte de un askari (soldado) marroquí de la hermana y una criada del doctor Jordán ${ }^{22}$. En Larache ejercía como delegado del Consejo Sanitario en 1885 el ya mencionado Francisco de Palma ${ }^{23}$. Dos médicos hebreos participaron en la red consular: los hermanos Mobily Güitta, Jacob y Samuel, licenciados en la Universidad de Sevilla. El primero estuvo destinado en el consulado de Rabat desde $1903^{24}$ y posteriormente se instalaría en Tetuán ya durante el Protectorado como médico de la Beneficencia Española y de la Israelita. El segundo comenzó como colaborador de Óvilo y Cenarro en el Hospital Español y la Comisión de Higiene. Al morir Cenarro, se convirtió de hecho en el representante español en este último organismo y en los que le sucedieron durante más de dos décadas ${ }^{25}$.

No todos los médicos españoles estuvieron encuadrados dentro de estas iniciativas regeneracionistas. Hubo al menos otros dos marcos operativos en este periodo. Uno de ellos pretendía asegurar la presencia española en el juego de influencias que Francia y Gran Bretaña tejían alrededor de la figura del sultán. Óvilo, después de haber sido recibido él mismo por Hassan I en 1887 y 1889 , conseguiría finalmente situar a un médico español en la corte para competir con el francés Jean Linarès, médico de la Misión militar francesa llegado a Marruecos en 1877, quien aprovechaba su proximidad al sultán para informar a sus superiores de los manejos de la corte. Fue en 1891cuando el médico militar Joaquín Cortés Bayona se incorporó a la "Comisión militar cerca del sultán de Marruecos” o "Misión Militar española cerca del sultán” que de forma discontinua consiguió residir en la corte y acompañar al

\footnotetext{
${ }^{20}$ AHMAE, Personal, P2029 Gustavo Prieto.

${ }^{21}$ Al Mogreb al-Aksa, 23 de agosto de 1885, 28 de abril de 1894.

${ }^{22}$ El Liberal, 16 de septiembre de 1889.

${ }^{23}$ Al Mogreb al-Aksa, 1 de noviembre de 1885.

${ }^{24}$ AHMAE, Personal, P 252, Expediente 14930 Doctor Güitta.

${ }^{25}$ LAREDO, Isaac, Memorias de un viejo tangerino, Rabat, Éditions La Porte, 1995, p. 144.
} 
sultán en sus desplazamientos hasta su supresión en 1893. Pero no sería hasta 1894, con motivo de la participación de Óvilo y Cortés en las negociaciones del general Martínez Campos con Hassan I en Marrakech para el pago de la indemnización de la guerra de Melilla de diciembre de 1893, cuando se consiguió el nombramiento del segundo como médico personal del sultán en Fez, puesto en el que permaneció hasta 1898. Tras Cortés, diversos médicos ocuparían el puesto clave de "agente consular" en Fez y/o "médico personal” del sultán hasta la creación del Protectorado francés. Entre ellos figuraron el ya mencionado Jacob Güitta (189726_1901), el médico de la Armada Alfonso Cerdeira Fernández (1902-1907) y el médico militar Francisco García Belenguer (1907-13), quien contribuyó decisivamente a la elección del jalifa de la zona española Muley el-Mehdi ${ }^{27}$. Durante esos años colaboraron con ellos en Fez el dentista José Cortés y el doctor Omar Barrada, de familia hispano-marroquí $(1903)^{28}$.

El último esquema médico se asoció a una importantísima iniciativa española: la Comisión del Cuerpo de Estado Mayor que recorrió diversas zonas de Marruecos levantando mapas, planos e itinerarios y redactando memorias político-militares entre 1882 y $1912^{29}$. La prematura muerte del primer jefe de la Comisión, Ramón Jáudenes, decidió al Ministerio de la Guerra a nombrar un médico militar que acompañara a los oficiales durante sus duras y a veces prolongadas campañas de recogida de datos. El primero en ocupar dicho puesto fue Adolfo Ladrón de Guevara, entre 1884 y 1887. Su labor sería continuada por Eloy Díaz Cassou (1887-88), Mariano López Rabadán (1888-90), Jerónimo Peralta Jiménez (1891-93) y los ya nombrados Fiol (1893-1903) y Triviño (1903-06) ${ }^{30}$. A diferencia de los médicos con-

${ }^{26}$ Al Mogreb al-Aksa, 20 de noviembre de 1897.

${ }^{27}$ MARTÍNEZ ANTONIO, Francisco Javier, "Entre la diplomacia médica y la política sanitaria: médicos militares en el Protectorado español en Marruecos (1906-1927)”, Revista de Historia Militar, no extraordinario 2, 2012, p. 203-242.

${ }^{28}$ GÓMEZ BARCELÓ, José Luis, "Las familias tetuaníes de origen español en el siglo XX”, en AOUD, Oumama; BENLABBAH, Fatiha (coords.) Españoles en Marruecos 1900-2007. Historia y memoria popular de una convivencia, Rabat, Instituto de Estudios Hispano-Lusos, 2008, p. 71 - 102.

${ }^{29}$ URTEAGA, Luis, Vigilia colonial. Cartógrafos militares españoles en Marruecos (1882-1912), Barcelona, Ministerio de Defensa-Bellaterra, 2006.

${ }^{30}$ MARTÍNEZ ANTONIO, Intimidades de Marruecos, p. 17. 
sulares, la mayoría había tenido destino en Filipinas o participó en la guerra de Melilla de $1893^{31}$. Al margen de cuidar de los miembros de la Comisión, estos médicos tuvieron la oportunidad, poco habitual en aquella época, de recorrer numerosas zonas del interior de Marruecos. En esos recorridos aprovechaban para ofrecer sus servicios gratuitos a notables marroquíes y a la población general, aunque su propósito estuviera fundamentalmente ligado al de sus compañeros cartógrafos: estudiar el territorio marroquí desde el punto de vista de su clima y enfermedades con vistas a preparar una eventual acción del ejército español.

\section{La producción científica: informes, manuscritos y publicaciones}

De lo expuesto en el apartado anterior se deduce que, si bien el número de médicos españoles presentes en Marruecos en este periodo no era muy elevado (entre 10 y 15), dichos médicos ocuparon posiciones de gran responsabilidad y se desplegaron por amplias zonas del territorio marroquí. En consecuencia, la producción científica de este periodo se aproximó como nunca lo haría después a elaborar una imagen general de la salud y la enfermedad en Marruecos y a proponer medidas para mejorar la condición sanitaria del país. Y esto a pesar de que la mayor parte de los trabajos elaborados por los médicos españoles en estos años no llegó a publicarse, bien por tratarse de informes manuscritos (confidenciales o no) enviados a los ministerios de Guerra y Estado o presentados en organismos como el Consejo Sanitario y la Comisión de Higiene deTánger; bien por tratarse de conferencias en sociedades científicas o intelectuales ${ }^{32}$. A continuación presentamos una relación, todavía provisional, de los trabajos que hemos identificado hasta la fecha.

Entre ellos destacaron sin duda por su originalidad respecto al resto del corpus los de Felipe Óvilo. Óvilo había publicado antes del periodo considerado un notable estudio monográfico en francés, De l'influence du pèlerinage

${ }^{31}$ En Filipinas: Ladrón de Guevara, entre 1872 y 1882; López Rabadán al menos en la primera mitad de los años 80; Peralta en 1893-99. En la guerra de Melilla: Cassou y Triviño.

32 Además, no hemos conseguido localizar informes, manuscritos o publicaciones de los médicos civiles, que seguramente debieron de existir. 
marocain à la Mecque sur la propagation du choléra (27 páginas, Madrid,Tipografía de Manuel G. Hernández, 1882), resultado de una comunicación presentada en el IV Congreso Internacional de Higiene y Demografía celebrado en Ginebra. [3] Sin embargo, dicho trabajo corresponde a una etapa inicial de su producción sobre Marruecos (resultado de una primera y breve estancia en el país en 1877-78) que no descansaba todavía sobre los supuestos regeneracionistas que caracterizarían su obra posterior. A ésta pertenecía ya el breve estudio epidemiológico El cólera en Tánger. Memoria acerca de su aparición en Marruecos (22 páginas, Tánger, Imprenta de A. J. Lúgaro, 1895), cuyos datos utilizaría también en la conferencia que pronunció sobre el mismo tema en la Sociedad Española de Higiene el 21 de enero de $1896^{33}$. Además, Óvilo envió un cierto número de informes a ministerios en Madrid, como el titulado Escuela de Medicina y Dispensario español en Tánger. Reseña de su organización y trabajos (7 páginas, 31 de marzo de 1888, Madrid); unas “cartas" durante la epidemia de cólera de Tánger de 1895 que no he podido localizar ${ }^{34}$; e intervino en Projet d'établissement d'un lazaret a la pointe de Malabata (8 páginas, Tánger, Imprenta Abrines, 1901), o sea, las actas de la comisión internacional nombrada para la creación de un lazareto en Tánger en la que Óvilo participó junto a otros tres médicos, uno francés, uno inglés y uno alemán, y que sería su última iniciativa oficial en Marruecos ${ }^{35}$.

En contraste con Óvilo, el doctor Severo Cenarro, [4] a pesar de ocupar puestos cruciales en la sanidad de Marruecos, no dejó ninguna publicación. No obstante, en el marco del Consejo Sanitario de Tánger, presentó algunos informes que tuvieron gran eco destacando entre ellos el Rapport lu à la séance du 17 Octobre 1895 par le médecin-consulteur, Mr. le docteur Severo Cenarro, en el que reclamaba la utilización de la isla de Mogador como lazare-

${ }^{33}$ El Liberal, 23 de enero de 1896.

34 “Se han recibido en Madrid cartas del doctor Óvilo, de fecha 27 del mes de septiembre, en las que dice que el cólera toma incremento en Tánger y que la epidemia ha invadido a la colonia europea. Añade que noticias de Tetuán afirman que en esta población marroquí se extiende el cólera, y había 60 atacados. La proporción de defunciones es muy considerable”. El Siglo Futuro, 1 de octubre de 1895.

${ }^{35}$ Archivo General de la Administración (AGA), Fondo Histórico de Marruecos, 'Caja M-21. Exp. 3. 
to de forma permanente ${ }^{36}$. [5] Puede que también fueran redactados por él, aunque no llevaran su firma, diversos reglamentos y disposiciones aprobados por el Consejo en los años en que ocupó el puesto de médico consultor, por ejemplo, el Règlement en cas d'épidémie colérique (2 páginas, Tánger, Imprenta de G.T. Abrines, 1892) y el Règlement pour l'embarquement et le débarquement des passagers à Tanger (1 página, Tánger, 6 de diciembre de 1893) ${ }^{37}$. Parecido camino siguió el sucesor de Cenarro en Tánger, Joaquín Cortés, quien no solo no dejó ninguna publicación, sino que centró sus informes en cuestiones políticas y no científicas. El sucesor de Cortés, Francisco Triviño, tampoco tuvo apenas producción científica, a excepción de una memoria manuscrita elaborada durante su destino en el viceconsulado de Larache, que quedó inédita y que no hemos podido localizar, titulada Contribución al estudio de los servicios sanitarios y constitución médica de Larache $(1901)^{38}$.

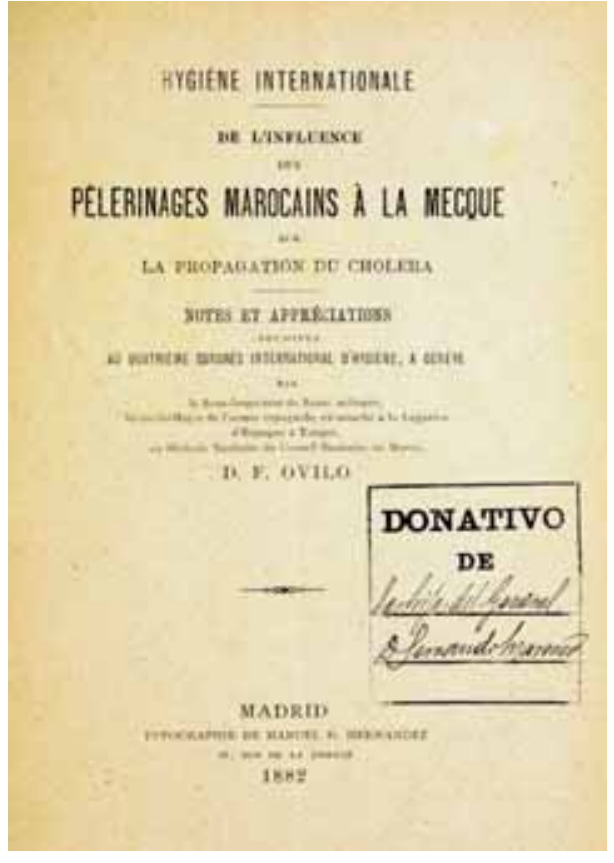

Fig. 3. Portadilla de De l'influence des pèlerinages marocains sur la propagation du choléra (1882). Fuente: www.bibliodef.es

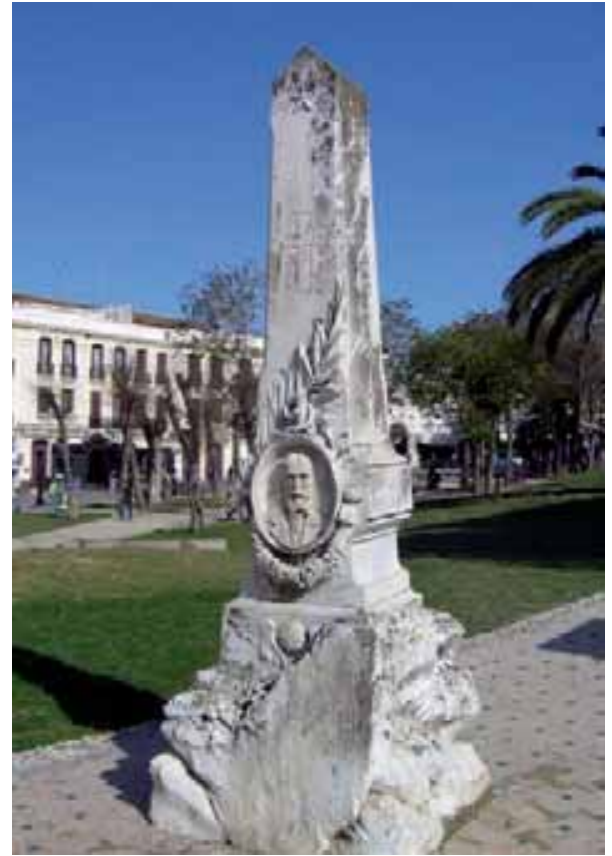

Fig. 4. Monumento en memoria del doctor Severo Cenarro en Tánger. Fuente: Francisco Javier Martínez Antonio.

\footnotetext{
${ }^{36}$ The National Archives (TNA), Foreign Office, 99, 374.

${ }^{37}$ Centre des Archives Diplomatiques de Nantes (CADN), Fonds Tanger, Carton 500.

${ }^{38}$ MARTÍNEZ ANTONIO, Intimidades de Marruecos, p. 36.
} 


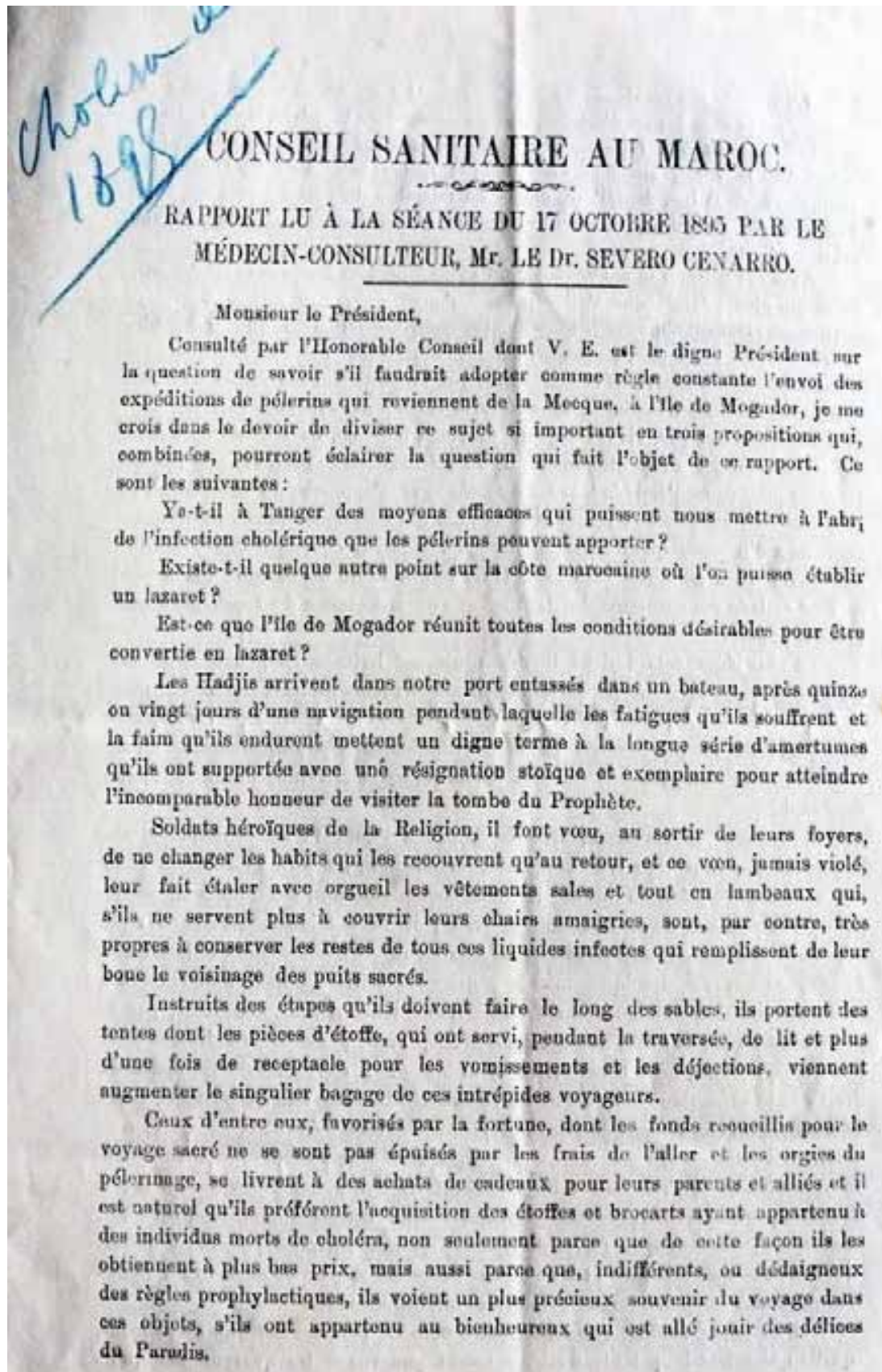

Fig. 5. Informe presentado por Severo Cenarro ante el Consejo Sanitario de Tánger, 1895. Fuente: Centre des Archives Diplomatiques de Nantes. 
Precisamente los médicos consulares, frente a la escasez de trabajos de los facultativos con cargos de mayor responsabilidad, tuvieron mayor producción científica, tanto manuscrita, como publicada. Así, del doctor García Belenguer nos consta la publicación de un breve trabajo en la revista La Medicina Militar Española "La peste en Oporto (impresiones)" (2 páginas, octubre de 1899). Aunque no trataba sobre Marruecos, era el resultado de su comisión como "delegado sanitario" del Consejo de Tánger para estudiar el riesgo de difusión de la peste desde Portugal a aquel país. El doctor Ricardo Conejero López escribió una memoria manuscrita titulada Climatología y Patología de Larache, Marruecos (134 páginas, Cartagena, 1895) que precedió al trabajo ya mencionado de Triviño y que, al igual que aquél, quedó inédito a pesar de valerle la Cruz Blanca de $1^{\text {a }}$ clase del Mérito Militar ${ }^{39}$. Por su parte, el médico hebreo Jacobo Mobily Güitta publicaría el folleto Estudio descriptivo del Paludismo reinante en Fez el presente año de 1901 (19 páginas, Sevilla, Francisco de P. Diaz, 1902). Finalmente, el “agente consular” en Fez, Alfonso Cerdeira, pudo enviar algún informe a los ministerios de Marina o Estado sobre los dispensarios que organizó en dicha ciudad tras ser nombrado "jefe de los servicios sanitarios en la corte del sultán” en octubre de 1905 o sobre la epidemia “de fiebres palúdicas y tifoideas" que castigó Fez al año siguiente ${ }^{40}$.

Con todo, fueron los médicos destinados en la Comisión de Estado Mayor los que realizaron más estudios y de mayor extensión. Así el doctor Ramón Fiol fue autor de un informe manuscrito que llevó por título Informe dado al Jefe de la Comisión de Marruecos, (126 páginas, 1894). Dicho trabajo serviría de base para una monumental Topografía médica del Fahz de Tánger y de las Kabilas de Anyera (3 volúmenes, 1051 páginas, 1899), memoria manuscrita preparada en Tánger y que quedaría inédita a pesar de valerle la Cruz Blanca de $1^{a}$ clase del Mérito Militar como a su colega Conejero ${ }^{41}$. Posteriormente, ya de regreso en España a resultas de haber contraído el paludismo al acompañar al jefe de la Comisión de Estado Mayor, Eduardo Álvarez Ardanuy, durante su destino como "agregado al ejército del sultán” en la primera gue-

\footnotetext{
${ }^{39}$ AGMS, Hoja de servicios de Ricardo Conejero López, C-3217.

${ }^{40}$ Archivo-Museo Don Álvaro de Bazán (AMAB), Hoja de servicios de Alfonso Cerdeira Fernández, legajo 2898/36.

${ }^{41}$ AGMS, Hoja de servicios de Ramón Fiol Jiménez, F-1478.
} 
rra civil marroquí de 1903, vería la luz su única publicación de tema marroquí, el artículo "La sífilis en Marruecos y las aguas de Muley-Jacob" en la revista La Medicina Militar Española (1903-04). Más suerte que su colega tendría otro médico de la Comisión de Estado Mayor, Jerónimo Peralta, cuyos Apuntes médicos de Marruecos. Topografía médica de Tetuán y su zona (121 páginas, Biblioteca de la Revista de Sanidad Militar, Madrid, Establecimiento Topográfico de Felipe Pinto y Orovio, 1894), [6] además de ser premiados por el Ministerio de la Guerra, serían publicados, tanto en su versión completa de monografía, como una parte de los mismos en la Revista de Sanidad Militar en forma de una serie de artículos titulada “Topografía médica de los terrenos comprendidos entre Wad-el-Martin y Wad-el-Laud, pertenecientes al bajalato de Tetuán” (1895). El primer médico de la Comisión, Adolfo Ladrón de Guevara, también dejaría varios trabajos inéditos y publicados. Los primeros fueron tres memorias manuscritas, fechadas en 1884 (145 páginas), 1885 (150 páginas) y 1887 (152 páginas), la primera de ellas sin título, las dos siguientes con el rótulo general de Memoria presentada al Sr. Jefe de la Comisión [...], referente a la expedición verificada durante los meses de... (enero a marzo de 1885 y agosto a octubre de 1886 , respectivamente). La tercera de ellas serviría de base para la publicación de una serie de ocho artículos en la Gaceta de Sanidad Militar bajo el rótulo Apuntes médicos de Marruecos (1888). [7] Finalmente, su sucesor Eloy Díaz Cassou redactó dos manuscritos en 1888, Informe médico sobre Tetuán y su zona (106 páginas) e Informe médico sobre Fez y su zona (114 páginas), centrados especialmente en las dos ciudades.

Terminaremos esta relación de trabajos con una contribución atípica. Se trata del folleto Les services sanitaires d'Espagne en Afrique (13 páginas, Madrid, Imprimerie du Depôt de la Guerre, 1900) escrito por el médico militar Ángel de Larra Cerezo. Decimos que es atípica porque Larra, a diferencia de todos los facultativos que acabamos de nombrar, nunca estuvo en Marruecos. No obstante, sus puestos técnicos dentro de la Sanidad Militar y su condición de editor de varias revistas médico-militares, le permitieron manejar mucha información con la que elaboró publicaciones sobre los servicios sanitarios del ejército español en la península, Cuba y África. En Les Services Sanitaires, Larra realizó un conciso pero completo recorrido por las instalaciones y personal del Cuerpo en Ceuta, Melilla y resto de plazas de soberanía, así como en territorio marroquí propiamente dicho. Este trabajo fue presentado en el X Congreso Interna- 
cional de Higiene y Demografía celebrado en París en agosto de 1900 siguiendo los pasos de Óvilo un par de décadas antes. [8] Larra también presentó una "contribución al estudio de la patología de Marruecos" en el XIII Congreso Internacional de Medicina celebrado en las mismas fechas en la capital francesa, pero no hemos podido localizar dicho texto.

\section{BIBLIOTECA DE LA REVISTA DE SANIDAD MILLTTAR

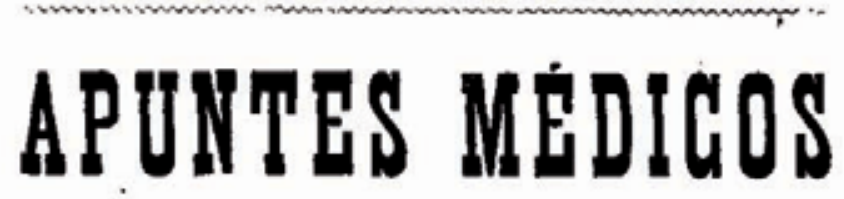

DE
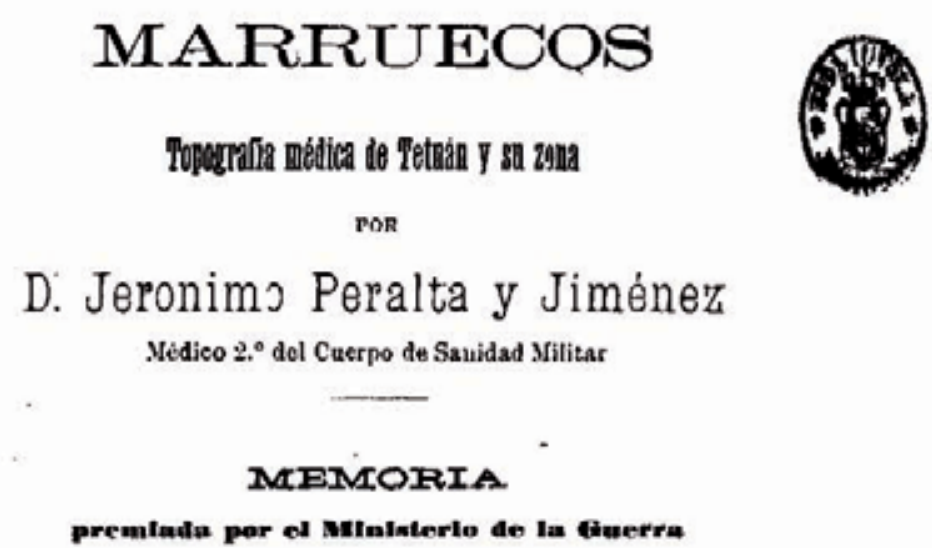

preminala por ed Milninterlo de la tiarerra
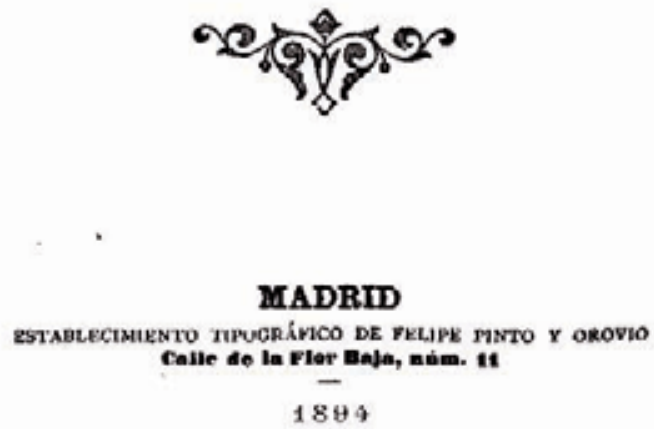

Fig. 6. Portadilla de Topografía médica de Tetuán y su zona (1894), de Jerónimo Peralta. Fuente: Revista de Sanidad Militar, Hemeroteca Digital de la Biblioteca Nacional de España. 


\section{$--170-$ \\ APUNTES MÉDICOS DE MARRUECOS \\ Compitsados Pun}

A. LADRON DE GUEVARA

Miaice $L^{\circ}$ de Sasidad Maiter.

FOIICIA MTEDIOA UREAIYA.

Los romanos, en su periodo de domínación, tanto en Mfarruecos como en otrag remotas colonias, á pesar de sus conquistas y de las memorablez épocas que la historia consigna, y de su más floreciente dominio civilizador y eulto en todo el mundo conocido de aquellos tiempos dejando á la postexidad eternas señales de su grandezs y poderio, desconocian mucho las debidas é higiénieas condiciones de salubridad, al establecer sus gran. des ciudades y centros prineipales de población, dando la preferencia $a$ la situación que mís les convenia, ya fuese agricola, milikar $\delta$ comercial. Quiak en aquellos tiempos, fuese otra la constitución del pais y su topo. Brafia, $y$ obedeciesea a un determinado sistems gabernativo, $y$ coloniza. dor, pues hoy se ven los eternos reatos de sus magnificas poblaciones, $y$ de sus formidableg obras en puatos lejanos de los actuales pueblos.

Muchos años antes de la dominación romana, estuvieron los fenicios y cartagineses explorando y colonizando el país, como demuestran muchas minas, entre ellas, las Chedla, en las ceroanias de Rabat y otras muchas, y las cronices de Hanuon y sus viajes.

Y después de los tiempos de León y de Belisario, sufrío el Imperio la conquista do los árabes $y$ la emigración de los moxos y judios de Portugal, España y otros paises en los tiempos de la reconquista.

Preseindiendo de detalles y recuerdos históricos que no son de este lugar, $y$ alargarian mucho estos apuntes, podremos decir, que tauto fenicios, oomo cartagineses, romanos, vándalos y árabes, y moros y judíos supieron aprovecharse de muchas apreciables circunstancias que shora nos aconвeja la higiene; $y$ luego los españoles y sobre todo los portugueses en sus conquistas del litoral, establecieron sus fuertes, colonias y cen. tros de comercio, en los puntos mís tavorables á todas las exigoneias, como veremos más adelsute, en el estudio de las principales poblaciones.

Si la situación de éstas, llena como hemos dicho en general, las ape. tecibles oireunstancias de higiénico emplazamiento, no sucede aoi on la actualidad, con las debidas de administración y policis urbana, que iremos anslizando.

En las cercanias de toda ciudad marroquí, no se ve máa que el deposito de toda la inmundicia y basura que neceesriamente arroja, y ouyas emanaciones pestilentes y malsanas, vician desde luego el aire, destinado á sanear el interior de aquélls, ya infecto.

Fig. 7. Primera página del artículo Apuntes médicos de Marruecos (1888). Fuente: Gaceta de Sanidad Militar, Hemeroteca Digital de la Biblioteca Nacional de España. 


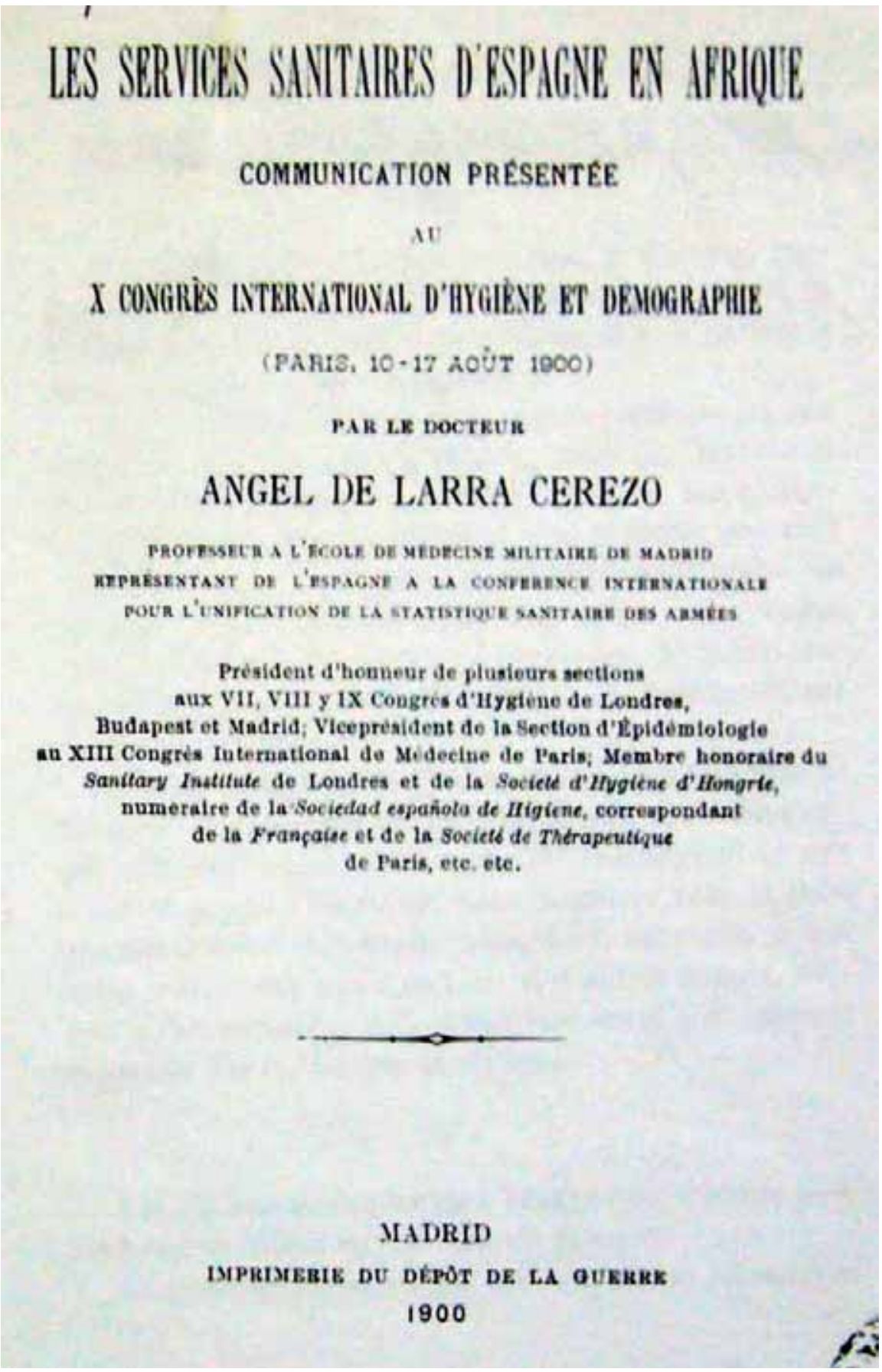

Fig. 8. Portadilla de Les services sanitaires d'Espagne en Afrique (1900), de Ángel de Larra y Cerezo. Fuente: Hemeroteca Digital de la Biblioteca Nacional de España. 


\section{Dos obras destacadas}

Para terminar este trabajo vamos a analizar con mayor detalle dos de las obras que acabamos de nombrar. Se trata de trabajos especialmente representativos de la producción médica española del periodo 1884-1906 por diversas circunstancias que trataremos de precisar. La primera de ellas es E1 cólera en Tánger del doctor Óvilo. [9] Como él mismo señalaba, este folleto de 22 páginas no pretendía ser un "estudio médico del cólera en Tánger", esto es, un artículo de investigación bacteriológica ${ }^{42}$. Podría haberlo sido, pues no en vano Óvilo fue el primer médico que aisló el bacilo de Koch en Marruecos, doce años después de que el sabio alemán identificara el germen de la enfermedad en Egipto. El médico militar tenía por entonces una larga experiencia del cólera en España, Cuba y Marruecos. Su primer contacto con la enfermedad había tenido lugar en la Gran Antilla durante la Guerra de los Diez Años, cuando tuvo que asistir a las fuerzas que actuaban en la región de Bayamo. Más importante fue que, en su primer destino en Tánger como médico agregado a la Legación en 1877-78, Óvilo fuera nombrado médico consultor del Consejo Sanitario y tuviera que tomar medidas para tratar de evitar la introducción de la epidemia en el país por peregrinos que regresaban de la Meca. Esta experiencia le sirvió como base para redactar su obra Influence du pèlerinage marocain à la Mecque..., la cual a su vez influiría en su folleto de 1895. En España, Óvilo publicó en 1883 y 1884 diversos trabajos de divulgación sobre la prevención de la enfermedad que se aproximaba a la península, dirigidos tanto a la población general como al ejército. A finales del último año fue enviado en comisión a Tolón por el Ministerio de la Guerra para estudiar el brote que había afectado a dicha ciudad y seguidamente fue nombrado representante español en la Conferencia Sanitaria Internacional celebrada en Roma en mayo-junio de 1885. De regreso a España, donde el cólera había hecho su aparición en marzo, participó en los debates que sobre la vacuna de Jaime Ferrán tuvieron lugar en la Sociedad Española de Higiene y el Ateneo de Madrid, fue nombrado miembro de diversas comisiones que lucharon contra la enfermedad en los cuarteles militares de varias

\footnotetext{
42 ÓVILO, Felipe, El cólera en Tánger. Memoria acerca de su aparición en Marruecos, Tánger, Imprenta de A. J. Lúgaro, 1895, p. 11.
} 
localidades españolas y también formó parte del equipo que estableció en el Laboratorio Histoquímico del Hospital militar de Madrid el germen del Instituto Anatomopatológico de Sanidad Militar, núcleo de la investigación histológica y bacteriológica en el ejército.

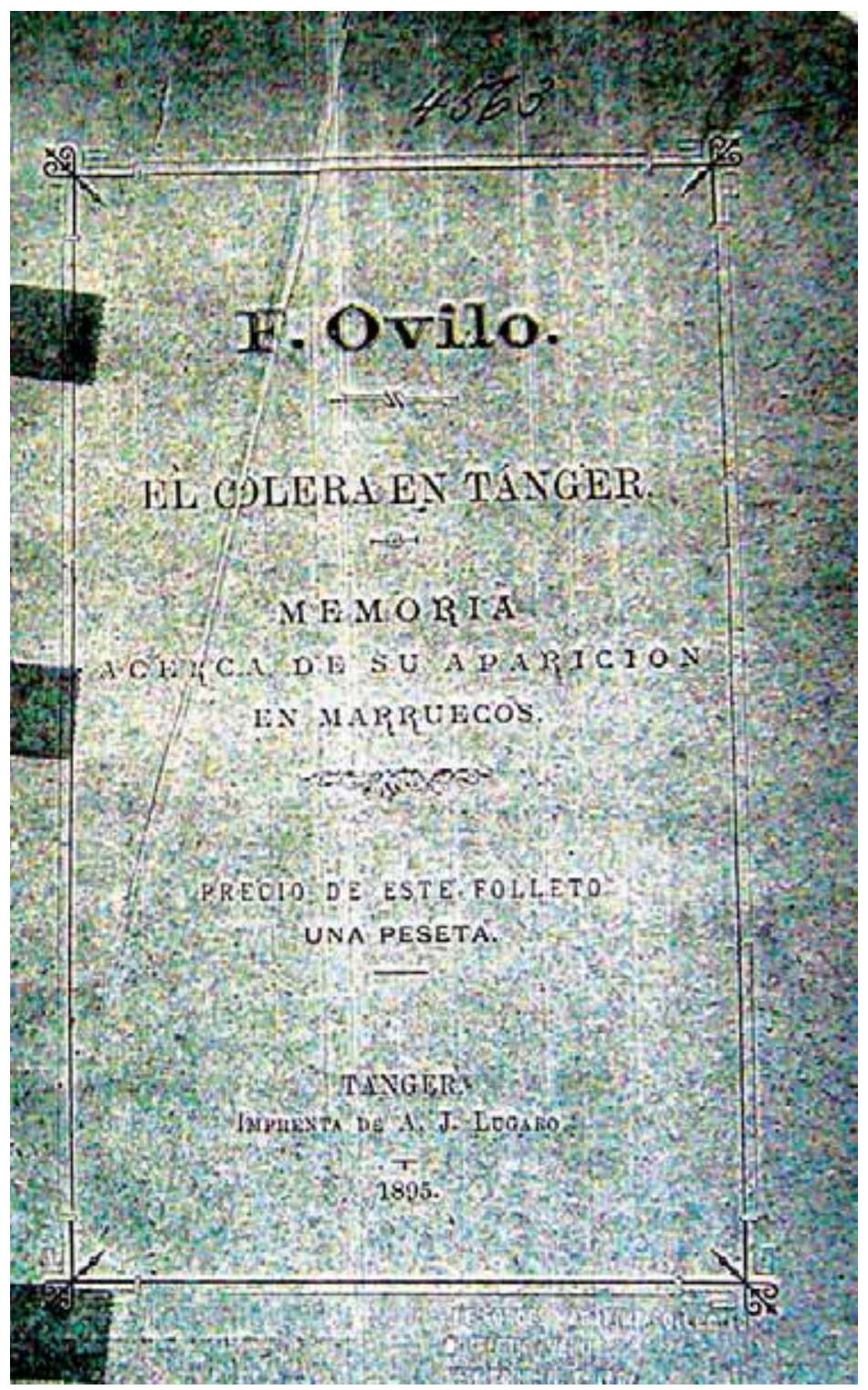

Fig. 9. Portadilla de El cólera en Tánger (1895), de Felipe Óvilo. Fuente:Tangier American Legation Museum. 
En definitiva, Óvilo tenía experiencia nacional e internacional sobre el cólera y le interesaba desde el punto de vista bacteriológico. En Madrid debió de realizar investigaciones en su laboratorio particular y en el del Laboratorio Histoquímico; en Tánger lo haría en el de la Escuela de Medicina, "provisto de lo necesario para un estudio, siquier sea elemental, concluyente" ${ }^{\text {. }}$. [10] Allí aisló el bacilo de Koch. La poca relevancia que concedió a este hecho en su folleto de 1895 se debió quizás a ciertas circunstancias desfavorables que tuvo que afrontar. Así, cuando la epidemia estalló a finales de agosto de 1895, Óvilo se encontraba con licencia (probablemente de vacaciones) en Madrid. A pesar de su salida inmediata hacia Marruecos, tuvo que esperar varios días en el puerto de Cádiz a que el buque Joaquín Piélago terminara su cuarentena. Dada la urgencia, su colega Cenarro decidió no esperarle y envió muestras de heces "contenidas en tubos de ensayo perfectamente obturados, y [que] procedían de un moro de la Alcazaba, que presentó síntomas coleriformes" al Instituto Anatomopatológico de Sanidad Militar de Madrid, donde se identificó el germen colérico tangerino antes que en Tánger ${ }^{44}$. A pesar de todo, Óvilo comenzó su trabajo de laboratorio nada más llegar y tras varios intentos consiguió "una placa en la que había tres colonias perfectamente caracterizadas del bacilo vírgula de Koch” ${ }^{\text {}}$. Sin embargo, en ese mismo momento cayó enfermo y hubo de suspender definitivamente sus investigaciones, aunque, en su opinión, éstas "solo podían tener ya por objeto un estudio puramente expeculativo [teórico]” puesto que el examen clínico de los enfermos confirmaba por sí mismo el diagnóstico de cólera ${ }^{46}$. Solo en los telegramas que envió a Madrid (y quizás en esas "cartas" oficiales que no hemos localizado) aparecieron detalles del trabajo de laboratorio de Óvilo":

"Examen deyecciones: aspecto baciforme característico; con microscopio, entre varias clases de bacterias, he visto un bacilo curvo igual que el de Koch, pero he empezado una serie de cultivos para diagnosticar seguro; el último en las mismas deyecciones me ha dado en esta ocasión un cultivo casi puro

\footnotetext{
43 ÓVILO, El cólera en Tánger, p. 10.

44 “El cólera en Tánger", Revista de Sanidad Militar, tomo IX, nº 99, 1895, p. 357-358.

45 ÓVILO, El cólera en Tánger, p. 11.

${ }^{46}$ Ibidem.
} 
de vibriones en forma de vírgula, formando cadenas onduladas con exóvulos dentro, tal como observó Tiukler [sic] en el esporádico" 47 .

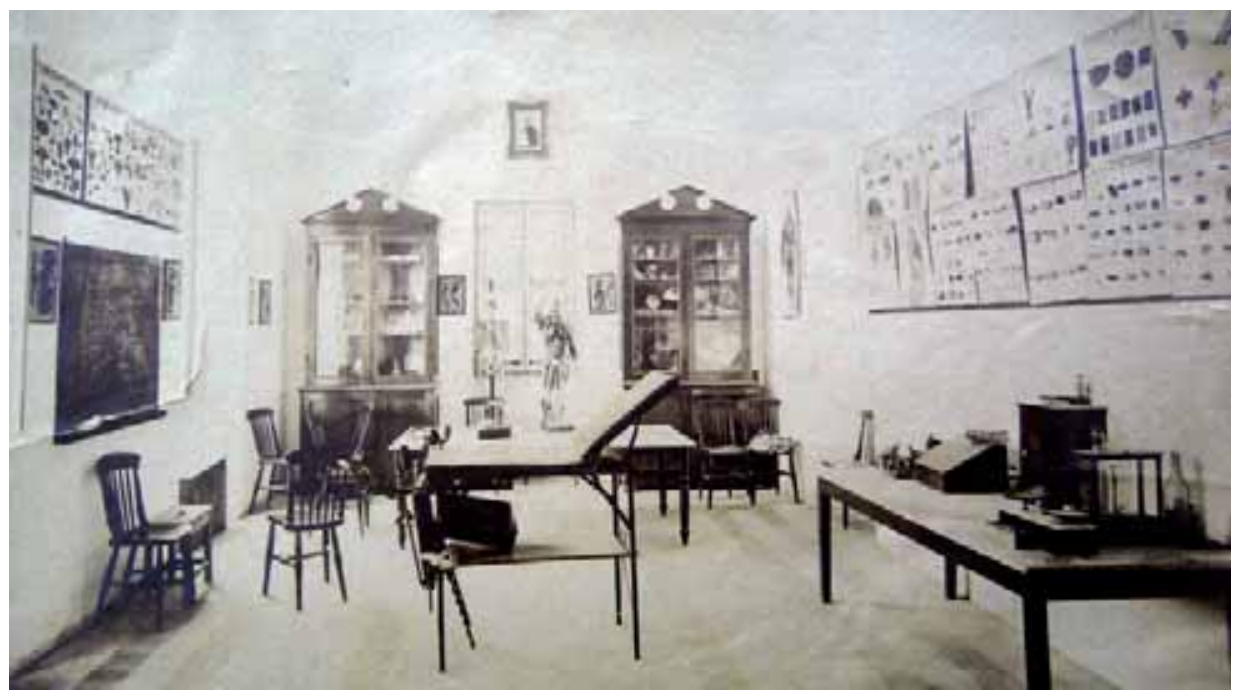

Fig. 10. Escuela de Medicina de Tánger, sin fecha. Fuente:Archivo de la Misión Franciscana en Tánger.

Quizás, no obstante, la falta de datos experimentales en El cólera en Tánger se debió más a que Óvilo nunca fue propiamente un bacteriólogo profesional. Para él, las competencias en bacteriología formaban parte de su más amplia condición de higienista y, por ello, siempre le interesaron más la epidemiología del cólera y, sobre todo, los factores sanitarios y sociales que influían en su origen y evolución. Estos aspectos son precisamente los que recibieron mayor atención en su folleto de 1895. Cabe destacar como principales aportaciones en este sentido, en primer lugar, su identificación de los peregrinos desembarcados por el vapor francés Maurice et Réunion el 17 de agosto como causa inmediata del brote. En contraste, el informe presentado ante el Consejo Sanitario por el médico francés Henri Soulié, subdirector del recién establecido Instituto Pasteur de Argel y que había sido enviado en comisión para estudiar la epidemia, quedó como un intento fallido de atribuir la enfermedad a la persistencia

\footnotetext{
${ }^{47}$ El Imparcial, 16 de septiembre de 1895. Hay aquí un error de transcripción por parte del periodista, ya que Óvilo cita correctamente en su folleto a Dittmar Finkler (1852-1912), médico alemán que publicó diversos trabajos sobre el “cólera esporádico” en los años 80.
} 
en Marruecos del germen colérico desde 1878 (lo que se conocía entonces como cólera nostras), estrategia destinada a exonerar de responsabilidad tanto a las compañías de navegación francesas, como a la sanidad argelina, que había concedido al buque patente limpia a pesar de los fallecimientos que se habían producido desde su salida de Alejandría ${ }^{48}$.

Otra aportación relevante de Óvilo fue su reconstrucción de la ruta epidemiológica del cólera en la ciudad. Señalaba el médico militar que, mientras que los peregrinos residentes en otros lugares de Marruecos acamparon en la playa y dejaron que el sol obrara "como benéfica y previsora estufa de desinfección” sobre sus ropas y equipajes, los oriundos de Tánger siguieron la costumbre habitual de pasar "unos días orando en el santo patrono del pueblo" ${ }^{\prime 9}$. En torno a la tumba de Sidi Buarrakia, situada en terreno del cementerio musulmán, se instalaron dichos peregrinos durante varios días y “del agua de sus pozos se sirven para todos sus menesteres, de ella beben, con ella hacen sus abluciones y por demás está decir que no se observan aquellos prolijos cuidados que hacen del agua de aquel pozo un agua higiénicamente potable" ${ }^{20}$. Estas condiciones hicieron que en el contiguo barrio de Bugaba "poblado por chozas de alquiler, muy barato, donde los vecinos pobres vivían almacenados” se presentase el primer foco epidémico, “desde donde había de repartirse el cólera por Tánger” ${ }^{51}$.La enfermedad se extendió después, por un lado, a los aduares vecinos y de allí a Tetuán y al Rif y, por otro, a Alcazarquivir, avanzando desde allí en tres ramificaciones hacia Fez, Mequínez y Rabat respectivamente ${ }^{52}$. Óvilo temía que las operaciones que el ejército del sultán preparaba en aquel momento terminaran por diseminar el cólera por todo el país. En todo caso, reconocía modestamente que su descripción carecía de "todo el rigor científico que puede exigirse en Europa" por la falta de médicos que le enviaran datos del interior del país ${ }^{53}$.

${ }^{48}$ CADN, Fonds Tanger A, Carton 167, Rapport de M. le docteur Soulié, sous-directeur de l'Institut Pasteur d'Alger en mission à Tanger. Tanger, le 8 Octobre 1895.

49 ÓVILO, El cólera en Tánger, p. 9.

${ }^{50}$ Ibidem.

${ }^{51}$ Ibidem.

52 Ibid., p. 14.

${ }^{53}$ Ibid., p. 15. 
En tercer lugar, Óvilo analizó las características concretas del brote. A su juicio había mostrado "muy poca fuerza expansiva", algo que consideraba habitual en Tánger ${ }^{54}$. Calculaba que la población musulmana se había visto afectada ocho veces más que la hebrea y la cristiana, aunque consignaba un foco "en un patio de vecindad de la playa entre los cristianos" 55 . La curva de morbi-mortalidad presentaba su forma habitual y así se podía deducir de la estadística que incluía al final del trabajo con los 1061 casos acontecidos entre el 6 de septiembre y el 2 de noviembre, estadística oficial, elaborada por Cenarro, que le había proporcionado el consulado español ${ }^{56}$. No obstante, consideraba que se debía añadir un 20\% más de fallecidos como mínimo si se quería tener una imagen real de la epidemia, lo que elevaba la tasa de mortalidad al 16x1000,"que no deja de ser importante" 57 . Con todo, en Tetuán había alcanzado el 3\%, "una de las mayores producidas en estos tiempos en la historia del cólera" ${ }^{58}$. Finalmente, una última aportación de interés la constituyó el relato de las medidas tomadas por los organismos sanitarios de Tánger para hacer frente a la epidemia. La más importante fue la delegación de poderes del Consejo Sanitario en la Comisión de Higiene presidida por Cenarro, la cual organizó un servicio de desinfección, propuso el derribo de chozas en el barrio de Bugaba y limpió las calles de la medina. Las autoridades sanitarias españolas tomaron medidas en la península y plazas de soberanía. Entre ellas, Óvilo fue nombrado ya en septiembre por el Director de Sanidad del Ministerio de la Gobernación, Marqués de Vadillo, "delegado sanitario" en Tánger para estudiar la enfermedad y recibió 4000 pesetas para "atender al saneamiento y desinfección de la colonia española de aquella plaza africana"59.

Discretamente como era el estilo de su autor, El cólera en Tánger reflejó el apogeo de la intervención española en la sanidad marroquí. Una intervención guiada por supuestos regeneracionistas y basada en la modernización de orga-

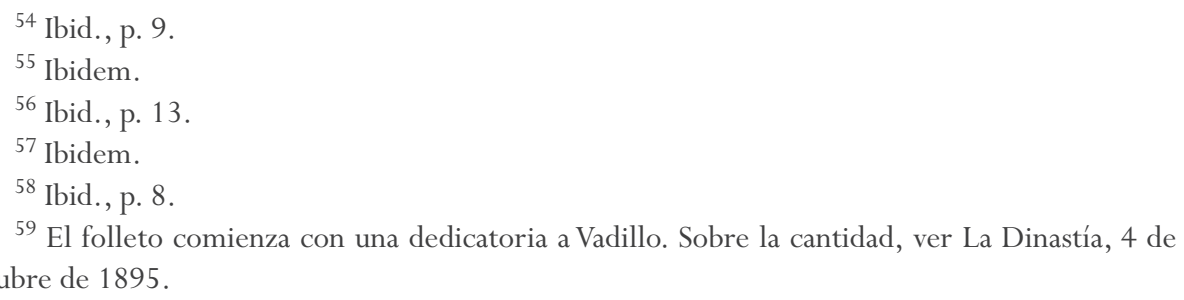


nismos locales ya existentes como el Consejo Sanitario y la creación de nuevas instituciones hispano-marroquíes como la Escuela de Medicina. Médicos españoles con trayectoria ultramarina y/o perfil internacional como Óvilo y Cenarro ocupaban puestos clave en la sanidad local, introducían la medicina de laboratorio en el país, formaban cuadros técnicos marroquíes o promovían la instalación de un lazareto permanente en Mogador. La lucha contra el cólera enTánger, verdadero centro del país y ciudad que todas las potencias europeas aspiraban a convertir en capital de su Marruecos colonial, aspiraba a marcar el camino a seguir en el resto de poblaciones y, en general, a sentar las bases de una política sanitaria marroquí. El contraste con los brotes de peste bubónica que afectaron a Marruecos en las décadas de 1910 y 1920 es notable. Para entonces Tánger había quedado excluido de las zonas de influencia y Protectorados francés y español y sus organismos e instituciones ejercían una interferencia percibida como perjudicial en la sanidad que comenzaba a organizarse en éstos últimos. A pesar de disponer de mejores medios, los médicos españoles no pudieron elaborar una imagen de conjunto de peste, puesto que carecían de datos sobre su origen y evolución en el Protectorado francés. Tampoco podían combatirla en su origen. Investigadores franceses como el doctor Paul Remlinger, director del Instituto Pasteur creado en Tánger en 1911, acaparaban el protagonismo por sus estudios científicos de la epidemia y sus medidas contra la misma.

La segunda obra de la que nos vamos a ocupar también constituyó un punto culminante de las actividades médicas españolas en Marruecos. La Topografía médica del Fahz de Tánger y de las Kabilas de Anyera fue el más importante de los trabajos científicos elaborados por los médicos agregados a la Comisión del Cuerpo de Estado Mayor. Su autor, Ramón Fiol Jiménez, [11] fue el médico que más tiempo permaneció al servicio de dicha Comisión, casi diez años entre 1893 y 1903. Ninguna atención ha recibido hasta ahora por parte de los historiadores. Nacido en Sevilla, Fiol debió de licenciarse en medicina allí y obtuvo el doctorado en Madrid en 1879 con la tesis El proceso hipotrófico histológica y químicamente considerado en sus diversas manifestaciones (58 páginas, Madrid, Establecimiento tipográfico de los señores M.P. Montoya y compañía, 1880 ${ }^{60}$.Tras

${ }^{60}$ Este trabajo también fue publicado como anexo en la revista La Medicina Militar española en 1899-1900. 
ingresar por oposición en el Cuerpo de Sanidad Militar, sus primeros destinos fueron el hospital militar de Cádiz ${ }^{61}$ y el regimiento de infantería de Córdo$\mathrm{ba}^{62}$. En diciembre de 1886 fue enviado al primer regimiento de infantería de Ceuta $^{63}$, donde preparó su segunda publicación Los modernos tratamientos del reumatismo articular agudo (18 páginas, Biblioteca de la Revista de Sanidad Militar, Madrid, Estudio Tipográfico de Ricardo Fé, 1887).

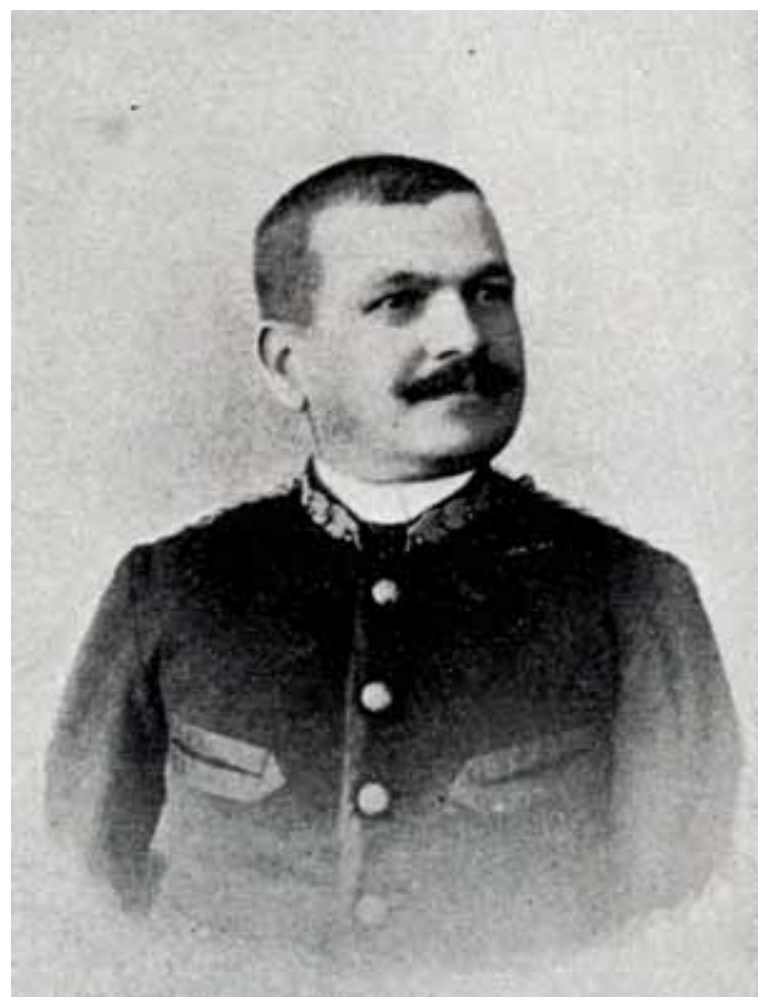

Fig. 11. Retrato del doctor Ramón Fiol. Fuente: Álbum-Escalafón del Cuerpo de Sanidad Militar del Ejército Español. Madrid, Est. Tip. Sucesores de Rivadeneyra, 1900. Biblioteca Digital Hispánica de la Biblioteca Nacional de España.

\footnotetext{
${ }^{61}$ Gaceta de Sanidad Militar, 25 de julio de 1880.

62 Gaceta de Sanidad Militar, 25 de septiembre de 1880.

${ }^{63}$ El Correo Militar, 21 de diciembre de 1886.
} 
En junio de 1893 pasó a la Comisión de Estado Mayor en sustitución de su colega, el también sevillano Jerónimo Peralta. La sede de la misma se trasladó en octubre desde Tetuán a Tánger "por motivos de seguridad" por lo que Fiol se instaló en esta última ciudad ${ }^{64}$. Las tensiones existentes entre España y Marruecos estaban detrás de esta medida preventiva y terminaron concretándose en enfrentamientos armados alrededor de Melilla en el mes de diciembre, que se saldaron por parte española con la muerte del general Margallo y un centenar de oficiales y soldados. Este clima pro-bélico permite entender las órdenes que recibió Fiol al poco de llegar a Marruecos y cuyo cumplimiento supuso el primer paso hacia la redacción de su Topografía. Con motivo del recorrido efectuado por la zona de Tetuán y Anyera en 1893-94 ${ }^{65}$, el jefe la Comisión, Servando Marenco, le ordenó elaborar un informe "acerca de las observaciones higiénicas que conviene tener presente en el probable caso de una invasión y ocupación por el ejército español del territorio comprendido entre Ceuta, Tánger y Tetuán”66. El resultado fue un manuscrito de 126 páginas que constituyó la contrapartida médico-higiénica a la primera hoja del Croquis de Marruecos a escala 1:50.000 levantado por los oficiales de Estado Mayor y al Proyecto de operaciones para la ocupación de la zona Ceuta-Tetuán adjunto al mismo. Los trabajos de ese Croquis, una empresa que pretendía imitar el levantamiento del Mapa Topográfico de España que llevaba a cabo por entonces en la península el Instituto Geográfico, prosiguieron en 1895 en Tánger y sus alrededores ${ }^{67}$. Fiol recorrió esa zona con la Comisión y a partir de las informaciones recogidas emprendió la redacción de su Topografía, que solo estaría lista en 1899 y que fue el equivalente médico de las Hojas 1 y sobre todo 2 del Croquis y asimismo de Acción militar de España en el Imperio de Marruecos (Bosquejo de un plan de campaña), informe redactado en 1896 y publicado en 1898 por Venancio Álvarez Cabrera, otro miembro de la Comisión.

La Topografía de Fiol era una obra monumental. Los informes de la Junta Consultiva y de la Sección de Sanidad Militar del Ministerio de la Gue-

${ }^{64}$ URTEAGA, Vigilia colonial, p. 156.

${ }^{65}$ Ibid., p. 161.

${ }^{66}$ Archivo del Servicio Geográfico del Ejército (ASGE), África, Índice de memorias e itinerarios descriptivos, Sanidad, Ramón Fiol, Informe dado al Jefe de la Comisión de Marruecos, Tánger, 14 de septiembre de 1894.

${ }^{67}$ URTEAGA, Vigilia colonial, p. 156, 161. 
rra que valoraron sus merecimientos para una recompensa mostraban su perplejidad ante "el erudito y vasto trabajo del Sr. Fiol [...], por traspasar los límites de lo corriente, tanto desde el punto de vista literario, como en el intrínsecamente científico" ${ }^{68}$. Como ya hemos señalado, su extensión era de 1051 páginas, agrupadas en tres volúmenes con la siguiente estructura:

\begin{tabular}{|c|c|c|c|}
\hline VOLUMEN & SECCIÓN & CAPÍTULO & APARTADO \\
\hline \multirow[t]{5}{*}{$\begin{array}{l}\text { Primero } \\
447 \text { p. }\end{array}$} & I. Topografía & $\begin{array}{l}\text { 1. Límites geográficos e historia 2. Orografía } \\
\text { Hidrografía 4. Comunicaciones 5. Duares, caseríos, } \\
\text { aldeas 6. Mercados 7. Tánger, historia8. Tánger, } \\
\text { geografía, urbanismo, aguas }\end{array}$ & \\
\hline & II. Historia natural & 1. Zoología 2. Botánica 3. Geología & \\
\hline & III. Agricultura & & \\
\hline & IV. Atmosferología & & \\
\hline & V. Climatología & & \\
\hline \multirow[t]{3}{*}{$\begin{array}{l}\text { Segundo } \\
135 \text { p. }\end{array}$} & I. Población & & \\
\hline & $\begin{array}{l}\text { II. Circunstancias } \\
\text { individuales e } \\
\text { higiénicas de los } \\
\text { habitantes }\end{array}$ & $\begin{array}{l}\text { 1. Caracteres antropológicos, temperamentos y } \\
\text { constitución predominantes } 2 \text {. Bromatología }\end{array}$ & \\
\hline & $\begin{array}{l}\text { III. Circunstancias } \\
\text { sociales y morales } \\
\text { de los habitantes }\end{array}$ & $\begin{array}{l}\text { 1. Idioma 2. Vestidos } 3 \text {. Nacimientos } \\
\text { 4. Matrimonios } 5 \text {. Entierros } 6 \text {. Religiosidad } \\
\text { 7. Beneficencia } 8 \text {. Vicios } 9 \text {. Justicia } \\
\text { 10. Propiedad 11. Instrucción pública } 12 \text {. Diversiones } \\
\text { públicas y fiestas religiosas }\end{array}$ & \\
\hline \multirow[t]{5}{*}{$\begin{array}{l}\text { Tercero } \\
489 \text { p. }\end{array}$} & I. Higiene pública & $\begin{array}{l}\text { 1. Estudio higiénico de Tánger y de los duares de la } \\
\text { zona } 2 \text {. Asistencia médica } 3 \text {. Adulteración de alimentos } \\
\text { y bebidas } 4 \text {. Vacunación y revacunación } 5 \text {. Prácticas } \\
\text { religiosas en relación con la higiene } 6 \text {. Instituciones }\end{array}$ & \\
\hline & II. Etiología & $\begin{array}{l}\text { 1. Causas derivadas de la topografía } \\
\text { 2. Circunstancias morales y sociales }\end{array}$ & $\begin{array}{l}\text { 2a. Edad 2b. Sexo } \\
\text { 2c. Raza 2d. } \\
\text { Alimentación 2e. } \\
\text { Cosmetología 2f. } \\
\text { Luz 2g. Oficios }\end{array}$ \\
\hline & III. Patografía & $\begin{array}{l}\text { 1. Aparato respiratorio 2. Aparato digestivo } 3 \text {. Bazo y } \\
\text { glándulas linfáticas } 4 \text {. Sífilis, blenorragia } 5 \text {. Piel } 6 \text {. } \\
\text { Meningitis } 7 \text {. Músculos y articulaciones } 8 \text {. Zoonosis } 9 \text {. } \\
\text { Aparato circulatorio } 10 \text {. Aparato respiratorio } 11 . \\
\text { Aparato digestivo } 12 \text {. Aparato génito-urinario } 13 . \\
\text { Sistema nervioso 14. Afecciones hemáticas } 15 \text {. } \\
\text { Trastornos nutrición 16. Patología externa } 17 . \\
\text { Enfermedades de los ojos } 18 \text {. Enfermedades de la piel } \\
\text { 19. Patología infantil 20. Enfermedades de la mujer } 21 \text {. } \\
\text { Frecuencia de las enfermedades }\end{array}$ & \\
\hline & IV. Terapia & $\begin{array}{l}\text { 1. Fisioterapia 2. Higioterapia 3. Farmacoterapia } 4 . \\
\text { Queiroterapia 5. Hidroterapia 6. Medicina de los moros }\end{array}$ & \\
\hline & $\begin{array}{l}\text { V. Estudio médico- } \\
\text { topográfico de } \\
\text { Tánger y su zona }\end{array}$ & & \\
\hline
\end{tabular}

${ }^{68}$ AGMS, Hoja de servicios de Ramón Fiol y Jiménez. 
La obra de Fiol pertenecía, según indicaba su título, al género de las "topografías médicas", un tipo de literatura científica iniciada por la medicina de la Ilustración ${ }^{69}$. Aunque en retroceso desde mediados del siglo XIX todavía se cultivó en muchos países y en particular en España. No se ha destacado, sin embargo, la importancia de la contribución de los médicos militares a este género en nuestro país, que se explica por medidas como la orden de1851 del Director General del Cuerpo de Sanidad Militar, Manuel Codorniu, que encargaba a sus jefes de distrito la elaboración de topografías médicas de sus respectivos territorios. En 1864, otro director del Cuerpo, José Santucho, señalaba que "ni siquiera podemos sospechar que haya quien ponga en duda la conveniencia de dichos estudios con aplicación a los deberes del instituto de Sanidad Militar. [...] No hay estudio que más se hermane con los deberes del médico militar" ${ }^{\text {70 }}$. De ahí que, en la exhaustiva relación de Casco Solís, el colectivo con mayor porcentaje de obras del periodo 1851-1906, excluyendo las de autoría anónima y quizás de los médicos de baños, es el de los médicos militares, quienes eso sí fueron casi los únicos en elaborar trabajos de ámbito regional, en contraste con la preferencia de los médicos civiles por ciudades, pueblos, comarcas y a veces provincias ${ }^{71}$. Así, hubo estudios médico-militares sobre Canarias, Baleares, Aragón, Cuba y Filipinas en ese periodo y, como ilustres precedentes de Fiol, los Apuntes topográficos sobre la parte del Imperio Marroquí que ha sido teatro de la última guerra con España (1860) de Fernando Weyler Laviña.

${ }^{69}$ CASCO SOLÍS, Juan, "Las topografías médicas. Revisión y cronología”, Asclepio, vol. LIII, $\mathrm{n}^{\circ} 1,2001$, p. 213-244.

${ }^{70}$ SANTUCHO, José, "Del clima de España bajo el aspecto médico y militar. Topografías médicomilitares”, Revista de Sanidad Militar Española y Extranjera, nº 22, 30 de noviembre de 1864, p. 525-530.

${ }^{71}$ De las 145 topografías identificadas por Casco Solís para ese periodo, 35 eran anónimas, 2 eran colectivas, 2 escritas por extranjeros, 9por médicos del ejército y3 por médicos de la Armada. Pero no constan en esa relación otras tres topografías de médicos militares que hemos localizado: GARCÍA VÁZQUEZ, Santiago, Apuntes médico-topográficos de la ciudad de Ceuta, Málaga, Imprenta de la Viuda de Herrero, 1855; CABEZA, Anacleto, Estudios sobre las Carolinas: la isla de Ponapé: geografía, etnografía, historia, Manila, Tipo-Litografía de Chofré, 1896; MITJAVILA, Jaime, Servicios sanitarios y topografía médica de la trocha de Mariel a Majana, Habana, Subinspección de Infantería, 1898. Los médicos civiles no constituían un colectivo uniforme pues había entre ellos médicos titulares, médicos de beneficencias provinciales y municipales, médicos de baños, médicos de hospitales, socios de Reales Academias de Medicina, etc. Además, algunas de las topografías de la lista fueron escritas por no médicos como Casiano del Prado o Vicente Paredes. 
La obra de Fiol formó parte de un corpus médico-topográfico sobre Marruecos que ascendió a 11 trabajos (que no figuran en la lista de Casco Solís), realizados por médicos militares destinados en la Comisión de Estado Mayor y en los consulados. En nuestra opinión, si la Comisión pretendía imitar en Marruecos el proyecto de levantar un mapa detallado de la península, que no se completó hasta mediados del siglo $\mathrm{XX}^{72}$, las investigaciones de sus médicos habrían sido equivalentes a los intentos, también lentos, de elaborar una "geografía médica” de España. El médico Manuel Iglesias Díaz promovió tal empresa desde la Real Academia de Medicina de Madrid a partir de 1886, pero sería una publicación ajena a tal iniciativa, La geografía médica de la Península Ibérica (1913) de Felipe Hauser (3 volúmenes, 1600 páginas), la primera que consiguió aproximarse a dicho objetivo ${ }^{73}$. La Topografía de Fiol habría sido el exponente más acabado de aquellas investigaciones marroquíes aunque, paradójicamente, no se inspiró en precedentes militares, sino que tomó como modelo explícito la Topografía médica deValencia y su zona (1878) de Juan Bautista Peset y Vidal, ejemplo a seguir en España hasta los trabajos de Hauser a comienzos del siglo XX. No solo imitó sus monumentales dimensiones (tenía 780 páginas impresas) sino que reprodujo la estructura general de la obra de Peset en la mayoría de sus apartados. [12 y 13]

La Topografía de Fiol se construyó sobre supuestos ideológicos y científicos distintos al estudio de Óvilo sobre el cólera. Los primeros se derivaban de su conexión con la Comisión, que en nuestra opinión constituyó una iniciativa asociada especialmente a la política marroquí de los gobiernos del Partido Conservador. En este sentido, los trabajos médicos, como los cartográficos y político-militares de la Comisión, habrían descansado no sobre un proyecto colonial, como se ha sugerido, sino de anexión de una parte de Marruecos a España. No había lugar en él para reformas de organismos locales o para la formación de médicos marroquíes, al estilo de las propuestas regeneracionistas de Óvilo, pero, a diferencia de una situación colonial,

\footnotetext{
${ }^{72}$ URTEAGA, Luis; NADAL, Françesc, Las series del mapa topográfico de España a escala 1:50.000, Madrid, Instituto Geográfico Nacional, 2001.

${ }^{73}$ CARRILLO, Juan Luis, "Un camino sembrado de espinas: Hauser y su aportación al enfoque ecológico en medicina”, en Entre Sevilla y Madrid: nuevos estudios sobre Hauser y su obra, Sevilla, Universidad de Sevilla, 1999, p. 37-38.
} 
marroquíes de la zona ocupada, "españolizados" a la fuerza, habrían podido formar parte de la nueva administración médico-sanitaria. Respecto a los supuestos científicos, la Topografía de Fiol constituía un tipo de trabajo más tradicional que el de Óvilo. La medicina moderna de finales del siglo XIX se hacía en los laboratorios de bacteriología, fisiología o histología a través de una siempre creciente aplicación de las ciencias básicas (física, química, biología, estadística matemática) al estudio de la salud y la enfermedad. En esta medicina, los artículos de revista comenzaban a ser considerados como instrumento central de comunicación de los resultados, aunque el papel de las monografías especializadas todavía fuera relevante. Las topografías médicas, por su carácter enciclopédico, por su débil fundamento experimental, por su extensión, constituían un tipo de trabajo cada vez menos frecuente y de menor impacto, incluso en España. Además, a pesar de que muchos higienistas españoles seguían valorándolas por su atención a los aspectos médico-sociales y ambientales, sus propios defensores, como el ya citado Hauser, reconocían que "con muy pocas excepciones, la mayoría de las topografías médicas existentes hoy en día en España carecen de valor científico, siendo construidas casi todas sobre un molde tradicional, hoy caduco, en vez de inspirarse en altos intereses sociales"74.

El hecho de que la Topografía de Fiol no fuera nunca publicada, como la mayoría de los trabajos de los médicos de la Comisión, fue una consecuencia de ambas cosas: sus supuestos político-militares implícitos favorecían el secretismo, sus supuestos científicos explícitos dificultaban su edición y difusión. En cualquier caso, se trató de un trabajo excepcional. Fruto de dos años de viajes por la zona de Tánger y de más de tres años de redacción, contiene una enorme cantidad y diversidad de observaciones. Pero este paso importante en el proyecto de elaborar una geografía médica de Marruecos no tendría continuidad ni equivalente en años posteriores. Tánger y su Fahs pasaron de región central y estratégica del Marruecos independiente y núcleo de las iniciativas españolas, a quedar fuera del Protectorado. Los trabajos de carácter médico-topográfico que se elaborarían durante décadas sobre algunas zonas de éste, como por ejemplo los Trabajos de un médico militar en el Rif(Beni Said) (1942) de Ignacio Iribarren, fueron ya insuficientes para dar una imagen de

\footnotetext{
${ }^{74}$ Cita de Hauser extraída de CARRILLO, “Un camino sembrado de espinas”, p. 36.
} 
conjunto de Marruecos. Eran, de hecho, muy poco representativos del país. En contraste, los médicos del Protectorado francés estuvieron más cerca de fijar una imagen de la "patología marroquí" o la "nosología marroquí" , identificable a nivel internacional y útil como base para el despliegue de una política sanitaria general.

\section{TOPOCRAPIA MÉDICA}

\section{DE VALENCIA Y SU ZONA,}

$\delta$

\section{APUNTKS PARA UXA MEDICINA PRÁGTICA VALEXELANA,}

Not en pocton

D. Juax Bautista Peset y Vidal,

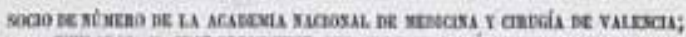

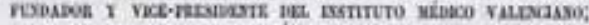

sodio ie whirro fee yisse

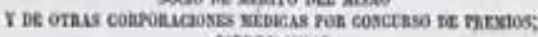
consestrosst.

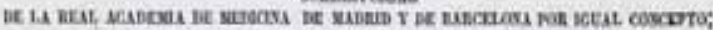

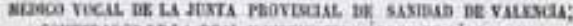

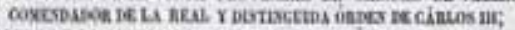

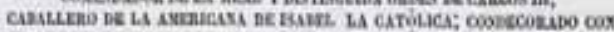

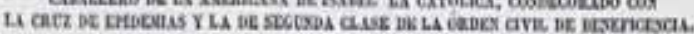

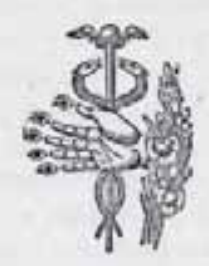

VALENCIA.

IMpnesta de Fenum de Orga,

Á espaldas del Teatro Prinelipal.

$18 \overline{7} 8$.

Fig. 12. Portadilla de Topografía médica de Valencia y su zona (1878), de Juan Bautista Peset. Fuente: Biblioteca Valenciana Digital. 


\section{ÍNDICE DE MATERIAS.}

Dedicatoria al Instituto Médico Valenciano como representante de las clases médicas. . . . Prólogo . . . . . . . . . . . . . . 7 TOPOGRAFIA MÉDICA DE VALENCIA. • 20 PARTE PRIYERA.

Esposicion de sus circunstancias topográficas.

\section{SECGION PRIMERA.}

Situacion de Valencia y descripcion de su zona. . 27

Cал. 1. ${ }^{\circ}$ Posicion geográfica. . . . . . 27

Carp. 2. ${ }^{\circ}$ Descripcion y límites de la zona de Valencia, sobre la que versa este trabajo. . . 28

SECCION SEGUNDA.

Historia natural de esta localidad.. . . . . 32

Gap. 1. ${ }^{\circ}$ Geología. . . . . . . . 32

Art. único. Nineralogía. . . . . . . 37

Cap. 2. ${ }^{\circ}$ Botánica ó Flora. . . . . . . 39

Art. 1. ${ }^{\circ}$ Vegetacion en el suelo erial. . . . $\$ 1$

Art. 2. ${ }^{\circ}$ Vegetacion cultivada. . . . . . 43

Art. $3 .^{\circ}$ Vegetacion acuática y marina. . . 44

Car. $3 .^{\circ}$ Zoología ó Fauna. . . . . $45^{\circ}$

Art. 1. Mastozoología ó Mammología (Mamíferos). . . . . . 47

Art. 2. ${ }^{\circ}$ Ornitología (Aves). . . . . . 89

Art. $3 .^{\circ}$ Erpetología (Reptiles). . . . . 50

Art. $4 .{ }^{\circ}$ Ictiología (Peces). . . . . . . 51

Art. 5. Entomología (Insectos). . . . . 52

Fig. 13. Extracto del “Índice de materias” de la 'Topografía médica de Valencia y su zona (1878),

de Juan Bautista Peset. Fuente: Biblioteca Valenciana Digital. 